\title{
KAJIAN POTENSI SUMBER ENERGI BIOGAS DARI KOTORAN TERNAK UNTUK BAHAN BAKAR ALTERNATIF DI KECAMATAN KALIREJO KABUPATEN LAMPUNG TENGAH
}

\author{
Untung Surya Dharma ${ }^{1)}$, Kms. Ridhuan ${ }^{2)}$ \\ Jurusan Teknik Mesin Fakultas Teknik, Universitas Muhammadiyah Metro ${ }^{1,2)}$ \\ email: untungsdh@yahoo.co.id
}

\begin{abstract}
Biogas is a source of energy that is derived from the decomposition of organic matter by microorganisms in the absence of oxygen (anaerobic) to produce a mixture of several gases are methane $\left(\mathrm{CH}_{4}\right)$ and carbon dioxide $\left(\mathrm{CO}_{2)}\right.$.Biogas can be made from many types of waste material and the rest, a kind of garbage, livestock waste, agricultural waste and others.Things to consider in the development of biogas energy source so that the principle of availability of sustainable biogas as an alternative fuel can be met is a local or regional potential to produce biogas.Communities in the District Central Lampung regency Kalirejo many who maintain livestock.Waste from livestock manure is especially very disturbing and detrimental to health, it is encouraging to capitalize upon the waste as feedstock for biogas production.To assess the potential of biogas energy sources are needed data about the amount of livestock manure every day, in this study is the dung of cows, goats and chickens. Fermentation process for the three types of dirt inside the reactor each trial was conducted to determine the length / time effective and energy biogas produced.From the field data known total number of chickens are farmed as much as 176.264, goat 12.345and cow 4.488 tail.Manure produced by 1 chicken, 1 goats and one cow in a row that is $0.055 \mathrm{~kg} /$ day, 0.98 $\mathrm{kg} /$ day and $19.5 \mathrm{~kg} /$ day. While the testing laboratory, known Biogas produced from each of $20 \mathrm{~kg}$ of dung that chicken manure yield of $2.04 \mathrm{~m}^{3}$, cow dung yield of $0.56 \mathrm{~m}^{3}$ and $0.76 \mathrm{~m}^{3}$ cow dung. From field data and laboratory testing can be calculated local potential in providing sustainable biogas in District Kalirejo Kalirejo Central Lampung regency, namely the potential of biogas from chicken manure at $988.84 \mathrm{~m}^{3} /$ day, goat manure at 338.75 $\mathrm{m}^{3} /$ day and cow manure at $3325.61 \mathrm{~m}^{3} /$ day. So the total potential of biogas that can be generated is equal to $4653.2 \mathrm{~m}^{3} /$ day.
\end{abstract}

Keywords: Biogas, local potentials, livestock manure, the total potential of biogas.

\section{PENDAHULUAN}

Saat ini krisis energy di negara kita mulai dirasakan masyarakat terutama dengan harga BBM yang semakin naik, yang mengakibatkan kelangkaan bahan bakar minyak seperti bensin dan solar di pasaran. Kelangkaan tersebut terjadi karena tingkat kebutuhan bahan bakar minyak semakin meningkat setiap tahunnya. Untuk menanggulangi masalah tersebut, pemamfaatan biogas sebagai bahan bakar alternative sangat mungkin diterapkan di masyarakat, terutama masyarakat di daerah yang jauh dari sumber energy bahan bakar fosil [1].
Satu hal yang perlu diperhatikan dalam penyedian sumber energy biogas agar azas ketersediaan biogas secara berkelanjutan sebagai bahan bakar alternative dapat terpenuhi adalah dengan memamfaatkan potensi lokal atau daerah dalam menghasilkan Biogas.

Kecamatan Kalirejo Kabupaten Lampung Tengah, cukup memiliki potensi tersebut. Daerah ini terkenal sebagai penyuplai hewan ternak seperti sapi, kambing dan ayam pedaging untuk konsumsi. Dengan semakin banyak hewan ternak artinya akan semakin banyak pula kotoran yang dihasilkan untuk kemudian dijadikan sebagai bahan baku pembuatan biogas. 
Menurut Indri Vaselina HarahapTahun 2009 [2] bahwa komposisi dari kotoran ternak seperti kotoran sapi mengandung gas methan sebanyak $65,7 \%$ dibandingkan gas lainnya. Gas methan inilah merupakan komposisi utama biogas.

Dengan mengetahui jumlah hewan ternak yang ada dan jumlah kotoran yang dihasilkan, serta pengujian untuk mengetahui jumlah biogas yang dapat dihasilkan oleh kotoran ternak, dalam penelitian ini yaitu sapi, kambing dan ayam pedaging maka diharapkan dapat diketahui potensi lokal di Kecamatan Kalirejo Kabupaten Lampung Tengah dalam menyediakan sumber energy biogas secara berkelanjutan sehingga perencanaan pemamfaatannya sebagai bahan bakar alternative kedepan dapat lebih terarah guna mendukung salah satu program pemerintah tentang kebijakan energi mandiri.

\section{LANDASAN TEORI}

Biogas merupakan suatu gas yang dihasilkan oleh bakteri metanogenik dari material - material yang dapat terurai secara alamiah dalam kondisi anaerobic [3]. Kandungan utama Biogas adalah gas metan $\left(\mathrm{CH}_{\mathbf{4}}\right)$ dan karbondioksida $\left(\mathrm{CO}_{\mathbf{2}}\right)$ [4]. Pada umumnya proses produksi biogas menggunakan alat yang disebut reactor biogas (digester) yang dirancang kedap udara sehingga proses penguraian oleh mikroorganisme dapat berjalan optimal $[5,6,7]$.

Menurut Indri V. Harahab Tahun 2009, limbah peternakan meliputi limbah padat dan limbah cair feses, urien, sisa makanan, embrio, kulit dan lemak. limbah peternakan merupakan salah satu sumber bahan yang dapat dimamfaatkan untuk mendapatkan biogas.

Menurut Update Guidebook on Biogas Development [8], kotoran hewan ternak dan manusia sangat berpotensi dalam menghasilkan gas. Potensi produksi gas dari berbagai jenis kotoran ternak dapat dilihat pada table 2, dimana terlihat bahwa kotoran unggas lebih berpotensi dalam memproduksi gas.
Tabel 1. Potensi Produksi Gas dari Berbagai Jenis Kotoran

\begin{tabular}{|c|c|}
\hline Jenis Kotoran & $\begin{array}{c}\text { Produksi gas per } \\
\mathbf{m}^{\mathbf{3}}\end{array}$ \\
\hline Sapi/kerbau & $\mathbf{0 , 0 2 3}-\mathbf{0 , 0 4 0}$ \\
\hline Babi & $\mathbf{0 , 0 4 0}-\mathbf{0 , 0 5 9}$ \\
\hline Unggas & $\mathbf{0 , 0 6 5}-\mathbf{0 , 1 1 6}$ \\
\hline Manusia & $\mathbf{0 , 0 2 0}-\mathbf{0 , 0 2 8}$ \\
\hline
\end{tabular}

Sumber : Update Guidebook on Biogas Development (1984) [8]

Adapun kandungan biogas menurut Sri Wahyuni, 2011 [9] dapat dilihat pada Tabel 2 di bawah ini.

Table 2. Komposisi Biogas

\begin{tabular}{|l|l|c|c|}
\hline No & \multicolumn{1}{|c|}{ Gas } & $\begin{array}{c}\text { Hadi } \\
(1981 \\
)\end{array}$ & $\begin{array}{c}\text { Price } \\
(1981)\end{array}$ \\
\hline 1. & Methan $\left(\mathrm{CH}_{4}\right)$ & $\mathbf{5 4 - 7 0}$ & $\mathbf{6 5 - 7 5}$ \\
\hline 2. & $\begin{array}{l}\text { Karbondioksida } \\
\left(\mathrm{CO}_{2}\right)\end{array}$ & $27-35$ & $25-30$ \\
\hline 3. & Nitrogen $\left(\mathrm{N}_{2}\right)$ & $\begin{array}{c}\mathbf{0 , 5}- \\
\mathbf{2 , 0}\end{array}$ & $\begin{array}{l}\text { Kurang } \\
\text { dari 1,0 }\end{array}$ \\
\hline 4. & $\begin{array}{l}\text { Hidrogen }\left(\mathrm{H}_{2}\right. \\
\text { ) }\end{array}$ & - & $\begin{array}{l}\text { Kurang } \\
\text { dari 1,0 }\end{array}$ \\
\hline 5. & $\begin{array}{l}\text { Karbon } \\
\text { Monoksida } \\
\text { (CO) }\end{array}$ & $\mathbf{0 , 1}$ & - \\
\hline 6. & $\begin{array}{l}\text { Hidrogen } \\
\text { sulfida }\left(\mathrm{H}_{2} \mathrm{~S}\right)\end{array}$ & Kecil & $\begin{array}{l}\text { Kurang } \\
\text { dari 1.0 }\end{array}$ \\
\hline
\end{tabular}

Sumber : Sri Wahyuni : 2011 [9]

Biogas yang komponen utamanya gas methan, dalam pemamfaatannya dapat diubah menjadi beberapa bentuk energy yaitu energy panas diubah menjadi energy mekanis dan dengan bantuan generator kemudian diubah menjadi energy listrik [10]. Sebagai contoh dapat dilihat pada Tabel 3 . 
Tabel 3. Konversi Energi Biogas dan Penggunaanya.

\begin{tabular}{|l|l|}
\hline Penggunaan & Energi $\mathbf{~ m}^{3}$ Biogas \\
\hline Penerangan & $\begin{array}{l}\text { Sebanding dengan } \\
\text { lampu 60 }-100 \text { W } \\
\text { selama 6 jam }\end{array}$ \\
\hline Memasak & $\begin{array}{l}\text { Untuk memasak 3 } \\
\text { jenis makanan untuk } \\
5 \text {-6 orang }\end{array}$ \\
\hline $\begin{array}{l}\text { Pengganti } \\
\text { Bahan Bakar } \\
\text { tenaga } \\
\text { pengangkut }\end{array}$ & $\begin{array}{l}\text { Sebanding dengan 0,7 } \\
\text { kg bensin } \\
\text { menjalankan motor 1 } \\
\text { pk selama 2 jam }\end{array}$ \\
\hline Listrik & $\begin{array}{l}\text { Sebanding dengan 1,2 } \\
\text { KWh litrik }\end{array}$ \\
\hline
\end{tabular}

Sumber : Kristoferson dan Bolkaders, 1991 [11]

Menurut Tuti Haryati, 2006 [12], keuntungan-keuntungan biogas sebagai energy alternative adalah sebagai berikut :

1. Harga bahan bakar yang terus meningkat

2. Dalam rangka usaha memperoleh bahan bakar lain yang dapat diperbaharui

3. Dapat diproduksi dalam skala kecil di tempat yang tidak terjangkau listrik atau energy lainya.

4. Dapat diproduksi dalam kontruksi yang sederhana.

\section{METODE PENELITIAN}

\section{Alat dan Bahan yang Digunakan}

\section{A. Alat yang digunakan}

Digester, ember, gayung, pengaduk, thermokopel, corong. Neraca digital. Tang, Obeng + -, Gergaji besi, Mesin bor, Kikir, Kompor biogas, selang gas, manometer, Penggaris, Meteran, Pukul besi, Pahat, Lap majun, Sarung tangga plastik, masker, Pena, kertas millimeter, spidol, papan, kerangan.

\section{B. Bahan yang digunakan}

Drum plastic kapasitas 90 liter, Pipa pvc 2 inch dan 0,5 inch, Lem pvc, Lem silicon, Lem plastic steel, Sambungan pipa T dan L 2 inch dan 0,5 inch, Katup pengatur/penutup, sealtips, plastik, tali karet pengikat

\section{Tahapan Pelaksanaan Penelitian}

\section{A. Tahap Pengumpulan Data Lapangan}

Pada tahap ini, pengumpulan data-data lapangan sangat diperlukan untuk perhitungan awal. Data lapangan ini dikumpulkan dengan cara observasi langsung di Kecamatan Kalirejo Kabupaten Lampung Tengah. Data-data tersebut adalah sebagai berikut:

a. Data banyaknya/jumlah masing-masing hewan ternak yaitu sapi, kambing dan ayam dan total keseluruhan hewan ternak.

b. Data jumlah kotoran yang dihasilkan masingmasing hewan ternak yaitu sapi, kambing dan ayam setiap harinya.

\section{B. Tahap Pengambilan data di Laboratorium.}

Pada Tahap ini, pengambilan data yang dilakukan merupakan data dari hasil pengujian sampel kotoran ternak yaitu sapi, kambing dan ayam di dalam reaktor uji coba. Adapun datadata yang dibutuhkan adalah sebagai berikut :

a. Data banyaknya kotoran ternak yang menjadi bahan baku biogas yang di fermentasikan didalam reaktor

b. Data lamanya waktu yang dibutuhkan untuk proses permentasi menghasilkan biogas.

c. Banyaknya biogas yang dihasilkan oleh reactor

\section{Tahap Analisa}

Pada tahap ini, analisa data dilakukan dengan cara membandingkan data bahan baku berupa kotoran hewan ternak rata-rata perhari dengan biogas yang dihasilkannya sehingga dapat diketahui seberapa besar potensi sumber energi biogas yang tersedia perharinya yang dapat dimamfaatkan sebagai bahan bakar alternative baik untuk kebutuhan rumah tangga maupun mesin penggerak pembangkit tenaga listrik. 


\section{HASIL DAN PEMBAHASAN}

\section{Hasil Pengumpulan Data Lapangan}

Dari hasil pengumpulan data lapangan yang dilakukan di 16 Desa di Kecamatan Kalirejo Kabupaten Lampung Tengah, didapat data dalam Tabel 4.

Tabel 4. Data Jumlah Hewan Ternak di Kecamatan Kalirejo Kabupaten Lampung Tengah

\begin{tabular}{|l|l|r|r|r|}
\hline \multirow{2}{*}{ No } & \multirow{2}{*}{ Desa } & \multicolumn{3}{|c|}{ Jenis Hewan Ternak } \\
\cline { 3 - 5 } & & Ayam & Kambing & Sapi \\
\hline 1 & \multirow{2}{*}{$\begin{array}{l}\text { Sri Way } \\
\text { Langsep }\end{array}$} & 26352 & 375 & 88 \\
\hline 2. & Wayakrui & 765 & - & - \\
\hline 3. & Kalirejo & 23430 & 846 & 132 \\
\hline 4. & Balai Rejo & 13701 & 889 & 513 \\
\hline 5. & Sri Basuki & 2853 & 915 & 166 \\
\hline 6. & Kali Wungu & 15234 & 910 & 159 \\
\hline 7. & Kalidadi & 5820 & 1470 & 268 \\
\hline 8. & Sri Mulyo & 3102 & 606 & 258 \\
\hline 9. & Sridadi & 13005 & 884 & 153 \\
\hline 10 & Sukosari & 11295 & 765 & 399 \\
\hline 11 & Watu Agung & 13321 & 747 & 910 \\
\hline 12 & Sinar Sari & 10521 & 753 & 315 \\
\hline 13 & Ponco Worno & 21798 & 1573 & 351 \\
\hline 14 & Sri Purnomo & 3021 & 591 & 168 \\
\hline 15 & Agung Timur & 10860 & 741 & 537 \\
\hline 16 & Sinar Rejo & 1199 & 280 & 71 \\
\hline Jumlah & 176264 & 12345 & 4488 \\
\hline
\end{tabular}

Adapun kotoran padat ternak yang dihasilkan rata-rata setiap harinya terlihat pada Tabel 5, dibawah ini :
Tabel 5. Data Jumlah Kotoran Padat Ternak Yang Dihasilkan

\begin{tabular}{|c|l|r|r|}
\hline No & \multicolumn{1}{|c|}{$\begin{array}{c}\text { Jenis } \\
\text { Hewan } \\
\text { Ternak }\end{array}$} & $\begin{array}{c}\text { Kotoran } \\
\text { Padat rata- } \\
\text { rata per ekor } \\
(\text { Kg/Hari })\end{array}$ & $\begin{array}{l}\text { Total Kotoran } \\
\text { (Kari) }\end{array}$ \\
\hline 1. & Ayam & 0,055 & 9694,52 \\
\hline 2. & Kambing & 0,98 & 12098,1 \\
\hline 3. & Sapi & 19,5 & 87516 \\
\hline
\end{tabular}

\section{Hasil Pengambilan Data Di Laboratorium}

Pada Tabel 6 dibawah ini, dapat dilihat data hasil dari penelitian yang dilakukan di laboratorium Jurusan Teknik Mesin Fakultas Teknik Universitas Muhammadiyah Metro tentang jumlah bahan baku dari kotoran ternak untuk pembuatan biogas dan total jumlah biogas yang dihasilkan. Adapun masa fermentasi kotoran didalam digester yaitu selama 60 hari. Dari pengujian, terlihat bahwa biogas mulai terbentuk pada hari ketiga hingga terakhir pengujian dengan volume biogas yang variasi, namun laju pembentukan biogas rata-rata dapat dihitung yaitu sebesar $0,036 \mathrm{~m}^{3} /$ hari atau 36 Liter/hari untuk berbahan baku kotoran ayam, $0,01 \mathrm{~m}^{3} /$ hari atau $10 \mathrm{Liter} / \mathrm{hari}$ untuk berbahan baku kotoran kambing, dan $0,0133 \mathrm{~m}^{3} /$ hari atau 13,3 Liter/hari untuk berbahan baku kotoran sapi. Digister yang digunakan dalam pengujian ini menggunakan system pengisian curah.

Tabel 6. Data Jumlah Kotoran yang menjadi bahan baku dan Biogas Yang dihasilkan

\begin{tabular}{|l|l|c|c|}
\hline No & $\begin{array}{c}\text { Jenis } \\
\text { Hewan }\end{array}$ & $\begin{array}{c}\text { Jumlah bahan } \\
\text { baku dalam } \\
\text { digester (air : } \\
\text { Kotoran) }\end{array}$ & $\begin{array}{c}\text { Jumlah } \\
\text { Biogas yang } \\
\text { dihasilkan }\end{array}$ \\
\hline 1. & $\begin{array}{l}\text { Kotoran } \\
\text { Ayam }\end{array}$ & $20 \mathrm{~kg}: 20 \mathrm{~kg}$ & $2,04 \mathrm{~m}^{3}$ \\
\hline 2. & $\begin{array}{l}\text { Kotoran } \\
\text { kambing }\end{array}$ & $20 \mathrm{~kg}: 20 \mathrm{~kg}$ & $0,56 \mathrm{~m}^{3}$ \\
\hline 3. & $\begin{array}{l}\text { Kotoran } \\
\text { Sapi }\end{array}$ & $20 \mathrm{~kg}: 20 \mathrm{~kg}$ & $0,76 \mathrm{~m}^{3}$ \\
\hline
\end{tabular}




\section{PERHITUNGAN DAN ANALISA}

Dari data lapangan yang telah dilakukan di 16 Desa di Kecamatan Kalirejo Kabupaten Lampung Tengah, jumlah rata-rata kotoran ternak yang dapat dijadikan bahan baku pembuatan biogas yang dihasilkan dari ketiga jenis hewan ternak yang banyak dipelihara yaitu ayam dengan rata-rata jumlah kotoran 9694,52 $\mathrm{kg} /$ hari, domba/kambing sebanyak $12098,1 \mathrm{~kg} /$ hari dan sapi sebanyak 87516 kg/hari.

Sedangkan dari data pengujian di Laboratorium Terpadu Fakultas Teknik Universitas Muhammadiyah Metro, didapat jumlah biogas yang dihasilkan dari masingmasing jenis kotoran ternak, secara beturut-turut adalah dari digester berbahan baku $20 \mathrm{~kg}$ kotoran ayam menghasilkan 2,04 $\mathrm{m}^{3}$ biogas, kotoran domba/kambing menghasilkan $0,56 \mathrm{~m}^{3}$ biogas dan kotoran sapi menghasilkan $0,76 \mathrm{~m}^{3}$ biogas. Untuk mendapat biogas secara berkelanjutan dilakukan dengan cara pengisian ulang bahan baku setiap harinya kedalam masing-masing digester sesuai dengan jenis kotoran.

Dari data-data lapangan dan hasil pengujian di laboratorium diatas, dapat kita ketahui seberapa besar potensi biogas yang ada di Kecamatan Kalirejo Kabupaten Lampung Tengah Profinsi Lampung, yaitu dengan cara menghitungnya sebagai berikut:

$$
\begin{gathered}
\text { Potensi Biogas }\left(\frac{\mathrm{m}^{3}}{\text { hari }}\right) \\
=j m l \text { kotoran ternak }\left(\frac{\mathrm{kg}}{\text { hari }}\right) x \mathrm{Jml} \text { Biogas } \\
\text { yang dihasilkan dari Kotoran ternak }\left(\frac{\mathrm{m}^{3}}{\mathrm{~kg}}\right)
\end{gathered}
$$

\section{Dimana :}

A. Jumlah kotoran ternak diketahui yaitu :

1. Kotoran Ayam $=9694,52 \mathrm{~kg} / \mathrm{hari}$

2. Kotoran Kambing $=12098,1 \mathrm{~kg} / \mathrm{hari}$

3. Kotoran sapi $=87516 \mathrm{~kg} / \mathrm{hari}$

\section{B. Jumlah Biogas yang dihasilkan dari kotoran} ternak,

\section{a. Untuk ayam :}

Untuk $20 \mathrm{~kg}$ kotoran ayam menghasilkan $2,04 \mathrm{~m}^{3}$ Biogas artinya $1 \mathrm{~kg}$ kotoran ayam menghasilkan $0,102 \mathrm{~m}^{3}$ atau dengan kata lain Jumlah biogas yang dihasilkan $0,102 \mathrm{~m}^{3} / \mathrm{kg}$ kotoran ayam.

\section{b. Untuk Kambing}

Untuk $20 \mathrm{~kg}$ kotoran kambing menghasilkan $2,04 \mathrm{~m}^{3}$ Biogas artinya $1 \mathrm{~kg}$ kotoran ayam menghasilkan $0,028 \mathrm{~m}^{3}$ sehingga Jumlah biogas yang dihasilkan $0,028 \mathrm{~m}^{3} / \mathrm{kg}$ kotoran kambing.

\section{c. Untuk Sapi}

Untuk $20 \mathrm{~kg}$ kotoran kambing menghasilkan $0,76 \mathrm{~m}^{3}$ Biogas artinya $1 \mathrm{~kg}$ kotoran ayam menghasilkan $0,038 \mathrm{~m}^{3}$ sehingga Jumlah biogas yang dihasilkan $0,038 \mathrm{~m}^{3} / \mathrm{kg}$ kotoran sapi.

\section{Hasil Perhitungan Potensi Biogas dari masing- masing kotoran}

\section{A. Untuk Potensi Biogas dari kotoran ayam adalah :}

$$
\begin{aligned}
& \text { Potensi Biogas dari kotoran ayam }\left(\frac{\mathrm{m}^{3}}{\text { hari }}\right) \\
& =9694,52\left(\frac{\mathrm{kg}}{\text { hari }}\right) \times 0,102\left(\frac{\mathrm{m}^{3}}{\mathrm{~kg}}\right)
\end{aligned}
$$

Potensi Biogas dari kotoran ayam

$$
=988,84\left(\frac{m^{3}}{\text { hari }}\right)
$$

$$
\begin{aligned}
& \text { B. Untuk potensi Biogas dari kotoran } \\
& \text { kambing adalah : } \\
& \text { Potensi Biogas dari kotoran kambing }\left(\frac{\mathrm{m}^{3}}{\text { hari }}\right) \\
& =12098,1\left(\frac{\mathrm{kg}}{\text { hari }}\right) \times 0,028\left(\frac{\mathrm{m}^{3}}{\mathrm{~kg}}\right) \\
& \qquad \text { Potensi Biogas dari kotoran kambing } \\
& =338,7468\left(\frac{\mathrm{m}^{3}}{\text { hari }^{3}}\right)
\end{aligned}
$$


C. Untuk potensi Biogas dari kotoran sapi adalah :

Potensi Biogas dari kotoran sapi $\left(\frac{m^{3}}{\text { hari }}\right)$

$=87516\left(\frac{\mathrm{kg}}{\text { hari }}\right) \times 0,038\left(\frac{\mathrm{m}^{3}}{\mathrm{~kg}}\right)$

Potensi Biogas dari kotoran sapi

$$
=3325,608\left(\frac{m^{3}}{h a r i}\right)
$$

\section{Hasil Perhitungan Potensi Total Biogas}

Adapun potensi total Biogas yang ada di Kecamatan kalirejo Kabupaten Lampung Tengah Profinsi lampung adalah :

Potensi Biogas yang ada $=$ Potensi Biogas dari kotoran ayam + Potensi Biogas dari kotoran kambing + Potensi Biogas dari kotoran sapi.

$$
\begin{aligned}
& =\quad 988,84 \mathrm{~m}^{3} / \text { hari }+338,7468 \mathrm{~m}^{3} / \text { hari }+ \\
& \quad 3325,608 \mathrm{~m}^{3} / \text { hari } \\
& =\quad 4653,2 \mathrm{~m}^{3} / \text { hari }
\end{aligned}
$$

\section{Analisa Hasil Perhitungan}

Dari perhitungan diatas terlihat bahwa jumlah total potensi biogas dari ketiga jenis kotoran ternak yang ada di Kecamatan kalirejo Kabupaten Lampung Tengah adalah sebesar $4651,2 \mathrm{~m}^{3} /$ hari . Adapun yang paling memiliki potensi untuk menghasilkan biogas adalah biogas yang berbahan baku kotoran sapi yaitu menghasilkan 3325,608 $\mathrm{m}^{3} /$ hari, sedangkan ayam hanya sebesar $988,84 \mathrm{~m}^{3} /$ hari dan kambing sebesar 338,75 $\mathrm{m}^{3} /$ hari (Gambar 3). Hal ini dikarenakan hewan tersebut dapat menghasilkan kotoran yang banyak sekali dibandingkan ayam dan kambing. Rata-rata 1 ekor sapi dapat menghasilkan 19,5 kg kotoran setiap harinya dibandingkan ayam dan kambing yang nilainya sangat kecil sekali hanya $0,055 \mathrm{~kg} / 1$ ekor ayam dan $0,98 \mathrm{~kg} / 1$ ekor kambing. Namun dari hasil pengujian, terlihat kotoran ayam memiliki potensi menghasilkan biogas yang paling besar per $\mathrm{kg}$ bahan baku kotorannya yaitu mencapai
$0,102 \mathrm{~m}^{3} / \mathrm{kg}$ dibandingkan sapi dan kambing yang hanya mencapai sepertiga nilainya yaitu $0,038 \mathrm{~m}^{3} / \mathrm{kg}$ dan $0,028 \mathrm{~m}^{3} / \mathrm{kg}$.

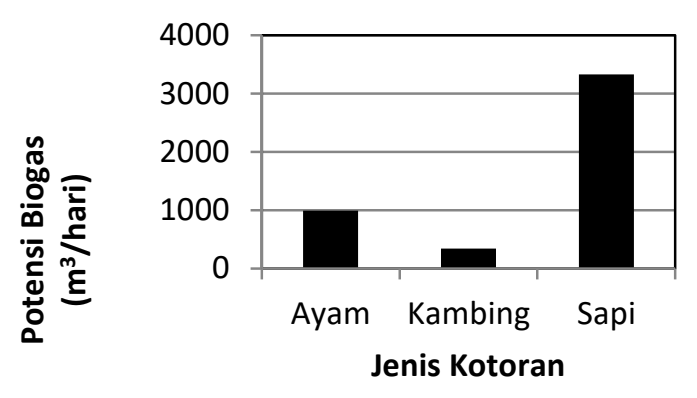

Gambar 1. Potensi Biogas dari Kotoran Ternak di Kecamatan Kalirejo

Dari data lapangan, Desa yang memiliki potensi biogas paling besar yaitu Desa Watu Agung dengan biogas yang dihasilkan yaitu sebesar $769,54 \mathrm{~m}^{3}$ /hari atau $16,54 \%$ dari total biogas yang dihasilkan di Kecamatan kalirejo dan berasal dari 13321 ekor ayam, 747 ekor kambing dan 910 ekor sapi, yang kedua Desa Balai Rejo dengan biogas yang dihasilkan 481,39 $\mathrm{m}^{3} /$ hari atau 10,35\% dan berasal dari 13701 ekor ayam, 889 ekor kambing dan 513 ekor sapi. Kemudian diikuti oleh Desa Agung Timur dengan biogas yang dihasilkan yaitu sebesar $479,18 \mathrm{~m}^{3} /$ hari atau 10,3\% dan berasal dari 10860 ekor ayam, 741 ekor kambing dan 537 ekor sapi. Dengan kata lain, 37,18\% dari potensi biogas yang ada di Kecamatan Kalirejo berasal dari ketiga desa tersebut sedangkan sisanya tersebar ke 13 desa lainnya. Dari data lapangan dan perhitungan diatas juga terlihat bahwa sapi adalah hewan ternak penghasil biogas yang paling dominan.

Menurut penelitian Tuti Haryati, 2006 [12], biogas apabila dibakar akan menghasilkan energy panas sekitar $252 \mathrm{Kkal} / 0,028 \mathrm{~m}^{3}$ dan menurut Sugi Rahayu dkk, 2009 [13] apabila $1 \mathrm{~m}^{3}$ biogas dibakar menggunakan oksigen maka akan menghasilkan nilai kalori sekitar 6000 watt jam atau setara dengan setengah liter minyak diesel dan 0,625 liter minyak tanah. Sedangkan menurut 
Kristoferson dan Bolkaders, 1991 [11], $1 \mathrm{~m}^{3}$ biogas setara dengan 1,2 KWh listrik dan $0,7 \mathrm{~kg}$ bensin. Dari penelitian-penelitian dan pernyataan-pernyatan peneliti terdahulu diatas, maka potensi biogas di Kecamatan kalirejo Kabupaten Lampung Tengah Profinsi Lampung secara sederhana dapat dikonversikan seperti pada Tabel 7 dibawah ini.

Tabel 7. Konversi Energi Biogas dan penggunaannya.

\begin{tabular}{|c|c|c|}
\hline $\begin{array}{l}\text { Energi } 1 \mathbf{m}^{3} \\
\text { Biogas }\end{array}$ & $\begin{array}{c}\text { Potensi Biogas } \\
=4653,2 \\
\mathrm{~m}^{3} / \mathrm{hari}\end{array}$ & Penggunaan \\
\hline $\begin{array}{l}1 / 2 \text { Liter } \\
\text { Minyak } \\
\text { diesel }\end{array}$ & $\begin{array}{l}\text { 9306,392 } \\
\text { Liter/hari } \\
\text { Minyak Diesel }\end{array}$ & Mesin Diesel \\
\hline $\begin{array}{l}\text { 0,625 Liter } \\
\text { Minyak } \\
\text { Tanah }\end{array}$ & $\begin{array}{l}7445,113 \\
\text { Liter/hari } \\
\text { Minyak Tanah }\end{array}$ & Memasak \\
\hline $\begin{array}{l}0,7 \mathrm{~kg} \\
\text { Bensin }\end{array}$ & $\begin{array}{l}6647,423 \\
\mathrm{~kg} / \text { hari bensin }\end{array}$ & Mesin Bensin \\
\hline $\begin{array}{l}\text { 1,2 KWh } \\
\text { listrik }\end{array}$ & $\begin{array}{l}3,878 \\
\text { MWh/hari } \\
\text { listrik }\end{array}$ & Penerangan \\
\hline
\end{tabular}

\section{KESIMPULAN}

Dari pembahasan sebelumnya, penelitian dengan judul Kajian Potensi Sumber Energi Biogas Dari Kotoran Ternak Untuk Bahan Bakar Alternatif Di Kecamatan Kalirejo Kabupaten Lampung Tengah dapat disimpulkan sebagai berikut :

a. Dari ketiga jenis kotoran ternak yaitu ayam, kambing dan sapi, dihasilkan total potensi biogas adalah sebesar $4653,2 \mathrm{~m}^{3} /$ hari dengan rincian yaitu kotoran ayam menghasilkan 988,84 $\mathrm{m}^{3} /$ hari, kotoran kambing menghasilkan $338,75 \mathrm{~m}^{3} /$ hari dan kotoran sapi menghasilkan $3325,61 \mathrm{~m}^{3} /$ hari biogas.

b. Dari hasil mengkonversikan $1 \mathrm{~m}^{3} /$ hari biogas menjadi bahan bakar, akan didapat dari total potensi biogas yang ada yaitu sebesar 4653,2 $\mathrm{m}^{3}$ /hari maka akan setara dengan 9306,392 L/hari minyak diesel, atau 7445,113 L/hari minyak tanah, atau $6647,423 \mathrm{~kg} / \mathrm{hari}$ bensin dan 3,878 MWh/hari Listrik.

\section{DAFTAR PUSTAKA}

[1] Chadijah Siti. Wiyoto. 2011. “ Konsep Teknologi, Renewable Energy “. Jakarta Selatan : Genta Pustaka .

[2] Indri Vaselina Harahap. 2007. “ Uji Beda Komposisi Campuran Kotoran Sapi Dengan Beberapa Hasil Limbah Pertanian Terhadap Biogas yang Dihasilkan ". Fakultas Pertanian Universitas Sumatra Utara.

Online_repository.usu.ac.id/bitstream/1234 56789/7524/1/09E00510.pdf_1

[3] Wahyuni Sri. 2009. “Biogas “. Bogor : Penebar Swadaya.

[4] Karki, A.B dan K. Dixit, 1984, Biogas Fieldbook. Sahayogi Press, Khatmandu, Nepal

[5] Ana Nurhasanah, dkk. 2009. “ Perkembangan Digester Biogas Di Indonesia "Litbang Deptan. Online_http://ntb.litbang.deptan.go.id/200 6/NP/perkembangandigester.doc

[6] Dewi Mayasari Herlina, dkk. 2010."Pembuatan Biodigister dengan Uji Coba Kotoran Sapi Sebagai bahan Baku”. Tugas Akhir, Program Studi DIII Teknik Kimia Fakultas Teknik Universitas Sebelas Maret Surakarta.

[7] Hamni, Arinal. 2008. "Rancang Bangun dan Analisa Tekno Ekonomi Alat Biogas Dari Kotoran Ternak Skala Rumah Tangga". Prosiding Seminar Hasil Penelitian dan Pengabdian kepada Masyarakat, UNILA, Bandar Lampung.

[8] Update Guidebook on Biogas Development Energy Resources Series. 1984. No. 27 United Nation, New York, USA.

[9] Wahyuni Sri. 2011. “ Menghasilakn Biogas Dari Aneka Limbah “. Bogor : Agro Media.

[10] Agus Krisno. 2011. “ Pemanfaatan Fermentasi pada Bakteri Limbah Kotoran Organisme untuk Menghasilkan Alternatif Bahan Bakar Masa Depan ". Wordpress, Online-diakses 18 November 2013.

[11] Kristoferson, L.A. dan V. Bokalders. 1991. Renewable Energy Technologies-Their Application in Developing Countries. ITDG Publishing. 
[12] Tuti Haryati, 2006. "Biogas : Limbah Peternakan yang Menjadi Sumber Energi Alternatif". Jurnal Wartazoa Vol. 16 No.3.

[13] S ugi Rahayu, Dkk. 2009. 'Pemamfaatan Kotoran ternak Sapi sebagai Sumber Energi Alternatif Ramah Lingkungan Beserta Aspek Sosio Kulturalnya”. Jurnal Inotek, Vol 13, No. 2. 